\title{
APPLICATION OF Ir-BASE ALLOYS TO NOVEL OXIDATION RESISTANT BOND-COATINGS
}

\author{
H. Murakami ${ }^{1}$, A. Suzuki ${ }^{2}$ F. Wu ${ }^{3}$, P. Kuppusami ${ }^{4}$, and H. Harada ${ }^{3}$ \\ ${ }^{1}$ Department of Materials Engineering, School of Engineering, The University of Tokyo, Tokyo, JP \\ ${ }^{2}$ Graduate School, Shibaura Institute of Technology, Tokyo, JP \\ ${ }^{3}$ High Temperature Materials Group, Mater. Eng. Lab., Natl. Inst. for Mater. Sci.(NIMS), Tsukuba, JP \\ ${ }^{4}$ Physical Metallurgy Section, Indira Gandhi Centre for Atomic Research, Kalpakkam, INDIA
}

Keywords: Ir-Ta, Ir-Pt, bond-coat, EB-PVD, electrodeposition

\begin{abstract}
High temperature oxidation and hot corrosion properties of Ir-Ta, Ir-Pt coated and aluminized coatings are presented. An Ir-Ta binary alloy, proposed as a novel metallic bond coat material, was coated on a Ni-base single crystal superalloy TMS-75 using electron beam physical vapor deposition (EB-PVD), followed by a conventional Al pack cementation process. Cyclic oxidation tests and hot corrosion tests revealed that these Ir-Ta coated and aluminized specimens showed reasonably good oxidation and hot corrosion resistance. In addition, the formation of TCP phases is suppressed by the presence of the Ir-Ta enriched layer. These results indicated that the Ir-Ta alloy system is promising as a new metallic bond coat for high temperature structural materials. On the other hand, substitution of Pt with $\mathrm{Ir}$ in Pt-Al coatings is of interest for cost reduction and strengtheneing purposes. Cyclic oxidation properties of (Ir, Pt)-coatings, which were successfully electrodeposited on TMS-75, followed by aluminization, were also investigated. Cyclic oxidation tests at $1373 \mathrm{~K}$ in air revealed that materials having better thermal cyclic oxidation resistance can be arranged in the following order: $\mathrm{Pt}-\mathrm{Al}=(36 \mathrm{at} \% \mathrm{Ir}, \mathrm{Pt})-\mathrm{Al}>$ Ir-Al $>>$ simply aluminized. The presence of Ir and/or Pt may promote the formation of dense and adherent oxide scale and thus retard the growth of thermally grown oxides. Ir addition is thus promising, not just in terms of cost reduction, but also expected solid solution strengthening.
\end{abstract}

\section{Introduction}

Ni-base superalloys are used in the hottest section of gas turbines due to their good balance of adequate strength, high level of resistance to corrosion, oxidation and erosion at high temperatures They are usually coated with a ceramic topcoat and an underlying metallic bond coat, such as NiCoCrAlY or aluminide in order to provide further oxidation protection to the superalloy substrate. However, recent demand in increasing the efficiency of turbines has led the components to be exposed at much higher operating temperatures. Under such circumstances, rapid interdiffusion of elements between substrates and bond-coats will promote the formation of detrimental TCP phases, resulting in the deterioration of mechanical properties of substrates. Therefore there is a great demand for improving the protective performance of a bond coat material which also acts as a "diffusion barrier" to prevent the formation of detrimental phases. With this in mind, we propose Ir-base alloys as bond coat materials because Ir has excellent oxidation and corrosion resistance and has the highest melting temperature $(2716 \mathrm{~K})$ among platinum group metals. It is also reported that the addition of Ir to Ni-base superalloys increase the melting temperature and thus may enhance the high temperature mechanical properties of the alloys [1]. In this study, we discuss the protective performance of several Ir-base alloys deposited on a Ni-base single crystal superalloy (TMS-75), followed by an Al-pack cementation process. Characteristics of IrTa alloys using an EB-PVD method, and electrodeposited Ir-Pt alloys are discussed in terms of oxidation and corrosion resistance.

\section{Experimental}

In this paper, all the substrates were prepared from a heat-treated Ni-base single crystal superalloy TMS-75 (Ni:63.1, Co:12.6, Cr:3.5, Mo:1.3, W:2., Al:13.7, Ta:2.0, Hf:0.04, Re:1.7 in at\%) [2,3]. The alloy was solution heat treated at $1573 \mathrm{~K}$ for $1 \mathrm{~h}$ followed by $1593 \mathrm{~K}$ for $5 \mathrm{~h}$ and gas fan cooled. A two-step aging treatment was then conducted, first at $1373 \mathrm{~K}$ for $4 \mathrm{~h}$, second at $1143 \mathrm{~K}$ for $20 \mathrm{~h}$, both followed by gas fan cooling to form coherent cuboidal $\gamma$ ' precipitates.

For EB-PVD, the heat treated TMS-75 was cut into $17 \times 17 \times 2$ $\mathrm{mm}$ plates, polished with emery paper up to \#600, and buffed with the $0.25 \mu \mathrm{m}$ diamond paste, and subsequently cleaned with acetone in an ultrasonic bath. An Ir-20at\%Ta alloy, fabricated by the vacuum arc melting method, was selected as a source material. The typical coating conditions were as follows, chamber pressure: $1.2 \sim 3.5 \times 10^{-3} \mathrm{~Pa}$ and an electron beam acceleration voltage of 10 $\mathrm{kV}$. Under these conditions, the typical deposition rate of approximately $10 \mu \mathrm{m} / \mathrm{h}$ was obtained for a single-sided coating. After that, the specimens were turned over and the other side of the specimens was coated. Entire surfaces including the edges were coated in this manner.

For electrodepositing Ir-Pt alloys, The substrates were cut into disks $10 \mathrm{~mm}$ in diameter and $2 \mathrm{~mm}$ in thickness. The electrolytes were prepared from amidosufuric acid, iridium chloride, chloroplatinic acid hexahydrate. Sodium nitrate was added to improve the conductivity. The nominal compositions of basic electrolyte are listed in Table 1.

Two platinum sheets were used as the counter electrodes with an area ratio of $2: 1$ to that of the specimens. The pretreatment procedure of the specimens prior to the electrodeposition consisted of following sequence: i) polishing with emery paper down to 2000 grit; ii) degreasing with acetone in an ultrasonic bath for 5 minutes; and iii) immersing the sample in a $30 \mathrm{wt} \%$ hydrochloric acid solution at $313 \mathrm{~K}$ for 5 minutes and then rinsing with distilled water. The $\mathrm{pH}$ value of the electrolyte was measured before and after every deposition ( HANNA pH meter 98108). In the event of a $\mathrm{pH}$ change, the value was corrected by adding $2 \mathrm{~N}$ hydrochloric acid solution or $1 \mathrm{~N}$ sodium hydroxide solution. In our study, all the experiments were carried out at controlled $\mathrm{pH}$ value of $2 \pm 0.2$. The electrolyte bath was stirred by a magnetic stirrer with a stirring speed of $60 \mathrm{rpm}$. The electrodeposition was conducted at the electrolyte temperature of $353 \mathrm{~K}$ and stirring with magnetic drum. The electrolyte temperature was controlled by constant temperature water bath with the accuracy of $\pm 2 \mathrm{~K}$. 
Typically coatings of $6 \mu \mathrm{m}$ in thickness were obtained for 60 minutes of electrodeposition.

The Ir-Ta and Ir-Pt-coated TMS-75 were then treated by a conventional pack-cementation aluminizing process, where these specimens were embedded in an $\mathrm{Al}_{2} \mathrm{O}_{3}$ retort containing a mixture of $\mathrm{Al}_{2} \mathrm{O}_{3}, \mathrm{Al}$ and $\mathrm{Fe}$ powder, and $\mathrm{NH}_{4} \mathrm{Cl}$. under flowing $\mathrm{Ar}$ atmosphere. The pack-cementation aluminizing treatment was carried out at $1373 \mathrm{~K}$ for $5 \mathrm{~h}$ for Ir-Ta coatings and $1273 \mathrm{~K}$ for $5 \mathrm{~h}$ for Ir-Pt coatings, respectively. For comparison, uncoated TMS75 was also aluminized under both conditions. Hereafter, these IrTa coated, Ir-Pt-coated and uncoated TMS-75 samples with Alpack cemented samples are denoted as (Ir, Ta)-Al-coated TMS-75, (Ir, Pt)-Al coated TMS-75, and simply aluminized TMS-75, respectively.

For the characterization of specimens at high temperatures, cyclic oxidation tests and hot corrosion tests were carried out in a programmable muffle furnace (Yamada Denki, MSFT-1500) at $1373 \mathrm{~K}$ in still air. The temperature variation in the furnace was controlled within $\pm 2 \mathrm{~K}$. Each thermal cycle consisted of $20 \mathrm{~h}$ at $1373 \mathrm{~K}$ and $4 \mathrm{~h}$ at ambient temperature and the tests were conducted up to 30 cycles. The oxidation resistance of the specimens was evaluated, in part, by the periodic weight changes of the specimens which were measured by a precision analytical balance with the accuracy of $\pm 0.05 \mathrm{mg}$.

Hot corrosion tests were conducted for (Ir, Ta)-Al-coated and simply aluminized TMS-75. Specimens dipped with $\mathrm{Na}_{2} \mathrm{SO}_{4}$ molten salts were heated at $1173 \mathrm{~K}$ for $20 \mathrm{~h}$ in air, followed by aircooling, which was defined as one heating cycle. This procedure was carried out up to 10 heating cycles.

The crystal structure, surface morphology, and composition of the coated layer and oxides were analyzed by X-ray diffraction (XRD: RINT-2000/PC, Cu/K $\alpha, 40 \mathrm{~V} / 300 \mathrm{~mA}$ ), scanning electron microscopy (SEM: Philips XL 30 with energy dispersive spectroscopy : EDS), and electron probe microanalysis (EPMA: JEOL JXA 9900R), respectively.

Table 1 Typical composition of Pt-Ir alloy electrolyte

\begin{tabular}{lc}
\hline Iridium chloride $\left(\mathrm{IrCl}_{3} \cdot 4 \mathrm{H}_{2} \mathrm{O}\right)$ & $0 \sim 40.0 \mathrm{~g} / 1$ \\
Chloroplatinic acid hexahydrate $\left(\mathrm{H}_{2} \mathrm{PtCl}_{6}\right)$ & $0 \sim 55.5 \mathrm{~g} / 1$ \\
Amidosufuric acid $\left(\mathrm{HOSO}_{2} \mathrm{NH}_{2}\right)$ & $38.0 \sim 48.0 \mathrm{~g} / 1$ \\
Sodium nitrate $\left(\mathrm{NaNO}_{3}\right)$ & $40.0 \sim 50.0 \mathrm{~g} / 1$ \\
& \\
$\mathrm{pH}$ (adjusted by $2 \mathrm{~N} \mathrm{HCl}$ or $1 \mathrm{~N} \mathrm{NaOH})$ & $1.8 \sim 2.2$ \\
Temperature $\left(T_{\mathrm{d}}\right)$ & $333 \sim 363 \mathrm{~K}$ \\
Current density $\left(i_{\mathrm{d}}\right)$ & $0.5 \sim 4.0 \mathrm{~A} / \mathrm{dm}^{2}$ \\
Magnetic stirring & $60 \mathrm{rpm}$ \\
Deposition time & $30 \mathrm{~min}$ \\
\hline
\end{tabular}

\section{Results and discussions}

3.1 Oxidation and hot corrosion properties of (Ir,Ta)-coated TMS-75

Oxidation resistance

The Ir-Ta alloy coatings, typically $8 \mu \mathrm{m}$ in thickness were deposited on TMS-75 using the EB-PVD method. The coated layer is uniform, dense without any compositional variations. However, the average composition in the coating layer is Ir-70 at $\% \mathrm{Ta}$, while the evaporation source is composed of $\mathrm{Ir}-20 \mathrm{at} \% \mathrm{Ta}$, indicating that the deposition rate of $\mathrm{Ta}$ is much greater than that of Ir. Though EB-PVD offers a possibility to deposit multicomponent alloy coatings with different compositions, there are certain factors, which need to be taken into consideration. The composition variation of the coating is ascribed to the relative

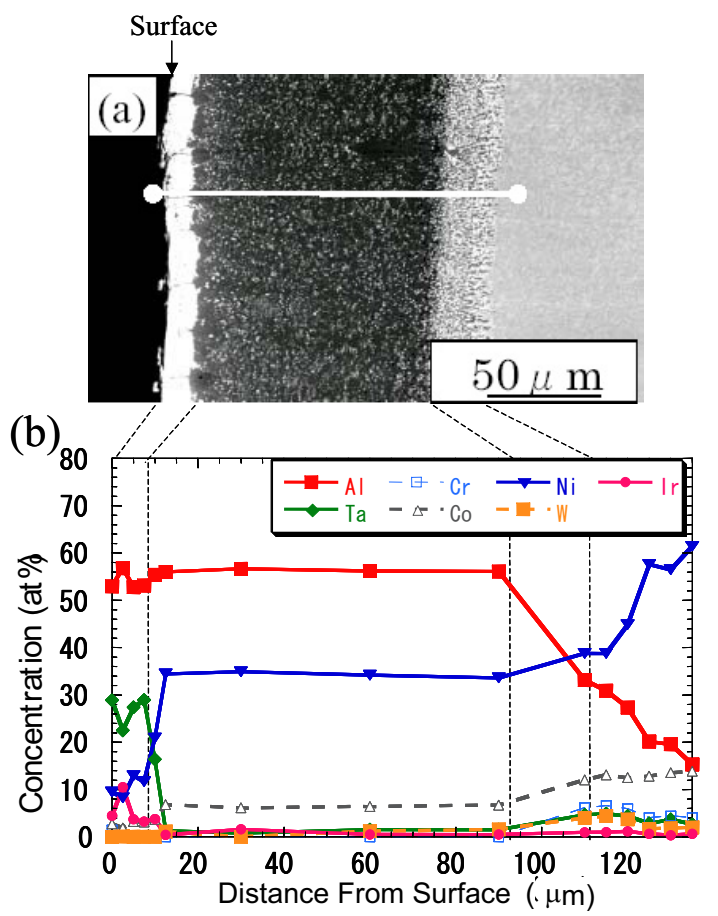

Figure 1: (a) Cross-sectional microstructure and (b) corresponding chemical composition profile of (Ir, Ta)-Al-coated TMS-75 [7].

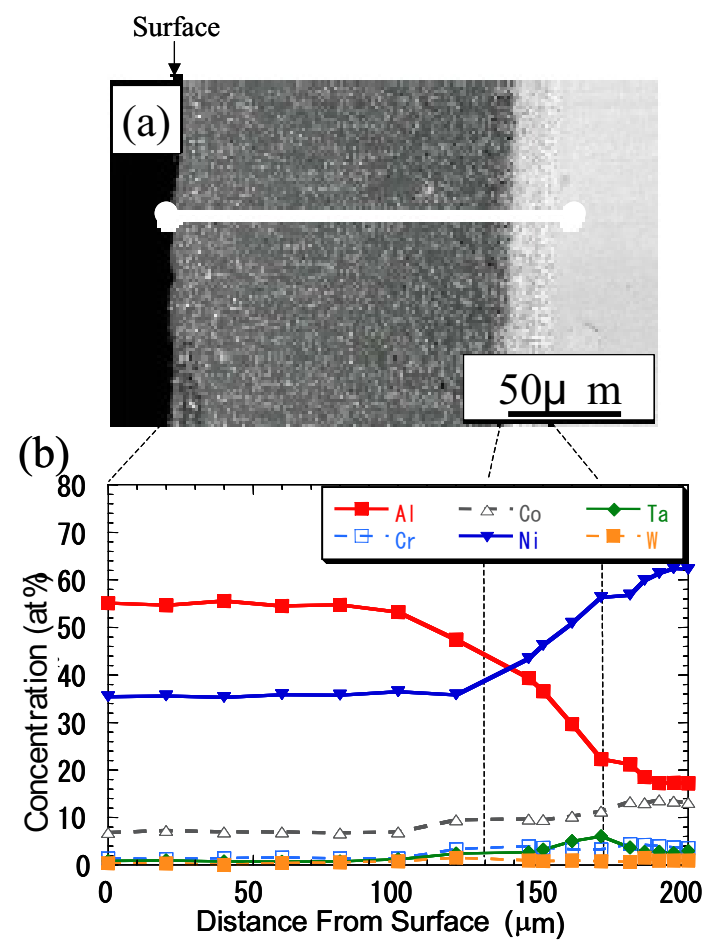

Figure 2: (a) Cross-sectional microstructure and (b) corresponding chemical composition profile of simply aluminized TMS-75 [7]. 


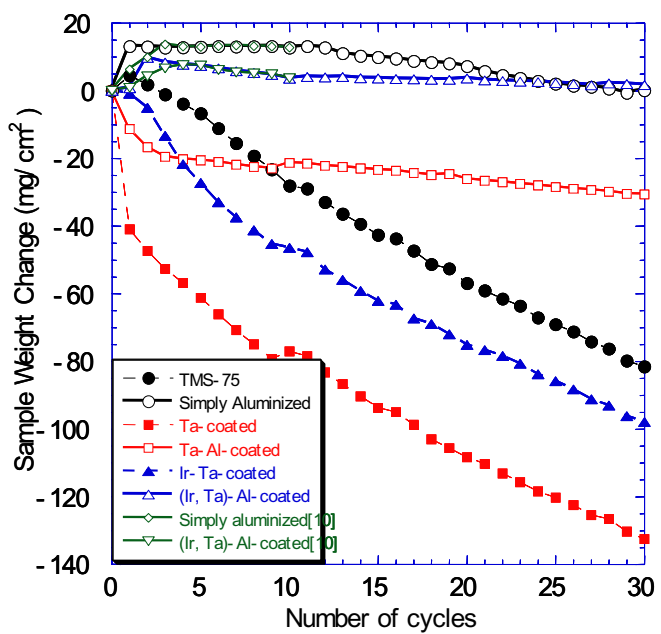

Figure 3: Kinetic oxidation curves of specimens as a function of oxidation cycle. Specimens were kept at $1373 \mathrm{~K}$ for 20 hours and air-cooled for each cycle.

vapor pressure of Ir and Ta, the temperature of evaporation source, the distance between the specimen and the source, the position of the specimen in the vapor cloud, and other processing parameters [4]. Since the interaction among these factors mentioned above is complicated, and remains unclear especially in the case of Ir and Ta co-deposition, a new approach to precisely control the Ir-Ta composition in the coatings by EB-PVD should be developed near future.

The specimens are then treated by the conventional Al-pack cementation process at $1373 \mathrm{~K}$ for 5 hours. Figures 1 and 2 show the cross-sectional microstructures and the concentration distribution of the elements for the (Ir, Ta)-Al-coated and simply aluminized TMS-75, respectively [5]. It can clearly be seen from Fig. 1a that the Ir-Ta-Al coated TMS-75 has a triplex layer structure, namely, an outer Ir-Ta-base alloy layer about $8-\mu \mathrm{m}$ thick, an intermediate $\beta$-NiAl-based layer about $100 \mu \mathrm{m}$ thick, and an inner Al-diffusion zone about $25 \mu \mathrm{m}$ thick. On the other hand, for the uncoated simply aluminized TMS-75 (Fig.4a), only a duplex layer structure is observed, $\sim 135 \mu \mathrm{m} \beta$-NiAl-based outer layer and $\sim 20 \mu \mathrm{m}$ Al-diffusion zone as the inner layer.

Figs $1 b$ and $2 b$ illustrate the concentration distribution of the elements measured along the entire cross section of the sample shown in Figs. 1a and 2a, respectively. For the (Ir, Ta)-Al-coated TMS-75 (Fig. 1b), the outer Ir-Ta base alloy layer contains about $50 \mathrm{at} \%$ of $\mathrm{Al}$ together with a small amount of $\mathrm{Ni}(\sim 5 \mathrm{at} \%)$ and $\mathrm{Co}$ $(1 \mathrm{at} \%)$ which may have outward-diffused from the substrate. The intermediate layer is mainly composed of $\beta$-NiAl with a small amount of $\mathrm{Co}, \mathrm{Ta}$, and $\mathrm{Cr}$. A part of Ta and very small amount of Ir may have inward-diffused from the coating during the packcementation aluminizing process. The inner layer below the $\beta$ $\mathrm{NiAl}$ layer is enriched with $\mathrm{Ta}$, and $\mathrm{Cr}$, forming an Al-diffusion zone accompanied by a coarsened $\gamma / \gamma^{\prime}$ structure. Although having slightly thicker intermediate and inner layers, the simply aluminized TMS-75 (Fig.2b) demonstrates a similar concentration profile to that of the Ir-Ta-Al coated TMS-75, except for the presence of Ir-Ta-Al enriched layer in the latter. In addition, precipitation of other phases was not observed in either sample.

The oxidation resistances of these aluminized specimens were investigated together with unaluminized specimens. Figure 3 shows the changes in weight of the (Ir, Ta)-Al-coated, Ta-Alcoated, and simply aluminized TMS-75, together with, unaluninized, (Ir, Ta)-coated TMS-75 and as-heat-treated TMS-75 as a function of oxidation cycles. The sample weight gain is mainly attributed to the oxidation of the surface, while weight loss is attributed to the exfoliation of volatile oxide scales from the specimen surface. Therefore, a sample demonstrating low weight

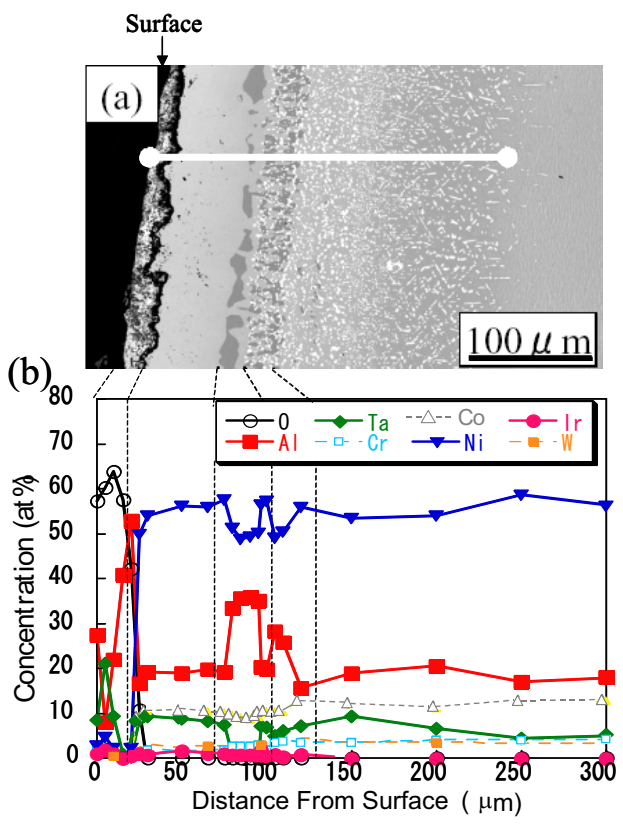

Figure 4: Change in (a) microstructure and (b) corresponding chemical composition profile of (Ir, Ta)-Al-coated TMS-75 after cyclic oxidation tests.

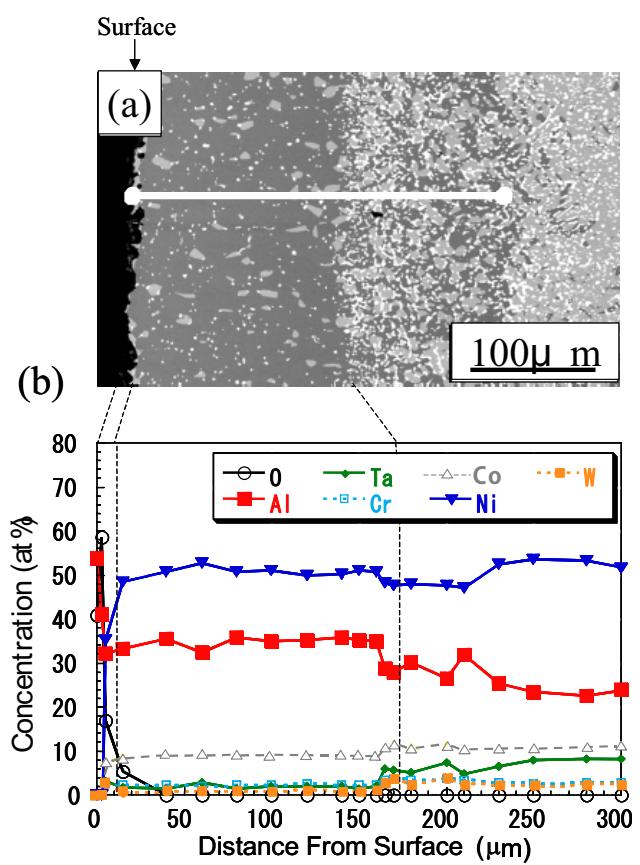

Figure 5: Change in (a) microstructure and (b) corresponding chemical composition profile of simply aluminized TMS-75 after cyclic oxidation tests 
change, especially low weight loss during this oxidation test, can be regarded as having a good oxidation resistance. As for unaluminized specimens, sample weight linearly decreased with a rate of approximately $2.25\left(\mathrm{mg} / \mathrm{cm}^{2}\right.$ per oxidation cycle) after several oxidation cycles, suggesting that these specimens had completely lost protective properties against oxidation. As for TaAl-coated and aluminized specimens, sudden decrease of weight after a few oxidation cycles is due to the spallation of surface layers. These results indicated that the (Ir,Ta)-Al-coated and simply aluminized TMS-75 have better oxidation resistance than the other specimens. However, for simply aluminized TMS-75, the sample weight increased after a few oxidation cycles and then became stable until 10th cycles. After that, the sample weight gradually decreased, suggesting that the spallation or exfoliation of surface oxidation layer started after 10 oxidation cycles. On the other hand, the weight change of (Ir,Ta)-Al-coated TMS-75 is much smaller than that of simply aluminized TMS-75, especially between the 10th and 30th oxidation cycles. For instance, the decrease in sample weight in ( $\mathrm{Ir}, \mathrm{Ta}$ )-Al-coated TMS-75 between the 10th and 30th cycles $\left(2.38 \mathrm{mg} / \mathrm{cm}^{2}\right.$, ) is about 4 times smaller than that in simply aluminized TMS-75 $\left(13.0 \mathrm{mg} / \mathrm{cm}^{2}\right)$, indicating that the former has better oxidation resistance at $1373 \mathrm{~K}$.

Oxidation at high temperatures can involve microstructural evolutions of substrate materials. Figures 4 and 5 show the (a) cross-sectional microstructure and (b) corresponding concentration profiles of solute elements in (Ir, Ta)-Al-coated (Fig. 4) and simply aluminized (Fig. 5) TMS-75 after 30 oxidation cycles.

It can clearly be seen from Fig.4a that an approximately $20-\mu \mathrm{m}$ thick surface oxide layer was formed on the (Ir,Ta)-Al-coated TMS-75. The Ir-, Ta-, Ni-and Al-enriched layer of about 50-60 $\mu \mathrm{m}$ thick remains under the oxide layer. Under that, a $\beta$-NiAlbased layer of about $30 \mu \mathrm{m}$ thick and an inner Al-diffusion zone being about 20 - $30 \mu \mathrm{m}$ thick were formed. It should be noted that TCP phases precipitated were observed only within $300 \mu \mathrm{m}$ in depth from the surface.

For the simply aluminized TMS-75 (Fig.5a), an outer oxide layer of about $10-\mu \mathrm{m}$ thickness was formed on the surface. Although the $\beta$-NiAl-based layer almost keeps its thickness of $\sim 160 \mu \mathrm{m}$, there are a number of TCP precipitates spread not only in the $\beta$ NiAl-based layer, but throughout the observed region. Also, the $\mathrm{Ni}$-content in the oxide layer is much higher in simply aluminized TMS-75 than in (Ir, Ta)-Al-coated TMS-75.

These microstructural changes occurring during oxidation tests can be explained in the following manner. When the aluminized specimens are exposed under hot air, the $\mathrm{Al}_{2} \mathrm{O}_{3}$ layer forms on the surface, which prevents the internal oxidation of the specimens. During oxidation tests, $\mathrm{Al}$ is continuously consumed in order to compensate for the spallation or evaporation of surface oxides. Simultaneously, interdiffusion between the Al-enriched layer and substrate occurs for the uniform distribution of solute elements. Consequently, inward diffusion of $\mathrm{Al}$ in the Al-enriched surface layer to the substrate and alternative outward diffusion of solute elements in the substrate to the surface, such as $\mathrm{Ni}, \mathrm{Cr}$, and $\mathrm{Co}$, occur during the oxidation tests. In addition, the concentration of $\mathrm{Al}$ in the surface area decreases with increasing oxidation cycles. These phenomena will lead to two detrimental effects, i) formation of brittle spinel oxides such as $\mathrm{NiAl}_{2} \mathrm{O}_{4}$ or volatile $\mathrm{NiO}$ and ii) precipitation of detrimental TCP phases in the substrate.

Thermodynamic investigation confirmed that $\mathrm{NiAl}_{2} \mathrm{O}_{4}$ or $\mathrm{NiO}$ forms when the aluminum activity is low and those of oxygen and nickel are high [6]. Once a uniform and dense $\mathrm{Al}_{2} \mathrm{O}_{3}$ layer forms on the surface, such secondary oxides would never form because the permeability of nickel into the $\mathrm{Al}_{2} \mathrm{O}_{3}$ scale is very low. However, cyclic thermal stress during the oxidation test may initiate cracks in the oxide scale. If $\mathrm{Ni}$ is present right beneath the cracked oxide layer, it can react with oxygen in the gas and/or $\mathrm{Al}$ to form $\mathrm{NiAl}_{2} \mathrm{O}_{4}$ and/or $\mathrm{NiO}$, due to the low $\mathrm{Al}$ activity ( $\mathrm{Al}$ concentration) at the reaction zone. The $\mathrm{NiAl}_{2} \mathrm{O}_{4}$ and/or $\mathrm{NiO}$ can then continue to grow by the transport (of oxygen gas) through the cracked $\mathrm{Al}_{2} \mathrm{O}_{3}$ layer. The slight decrease in weight for simply aluminized TMS-75 after 10 oxidation cycles can thus be explained by the spallation of brittle $\mathrm{NiAl}_{2} \mathrm{O}_{4}$, or exfoliation of volatile $\mathrm{NiO}$. Indeed, in our previous investigation, $\mathrm{X}$-ray analysis demonstrated the presence of $\mathrm{NiAl}_{2} \mathrm{O}_{4}$ and $\mathrm{NiO}$ in simply aluminized TMS-75 after 10 oxidation cycles [7]. In addition, $\mathrm{Ni}$ concentration in the oxide layer in (Ir, Ta)-Al-coated TMS-75 (less than 5 at \%) is much lower than that in simply aluminized TMS-75 (typically 30 at $\%$ ) after 30 oxidation cycles, as shown in Fig. 4(b) and Fig. 5(b), respectively. These results support the above discussion. On the other hand, (Ir, Ta)-Al-coated TMS-75 maintains stable $\mathrm{Al}_{2} \mathrm{O}_{3}$-based surface layer even after 30 oxidation cycles, resulting in the smaller mass change $(2.38$ $\left.\mathrm{mg} / \mathrm{cm}^{2}\right)$ than that of simply aluminized TMS-75 $\left(13.0 \mathrm{mg} / \mathrm{cm}^{2}\right)$ from 10 to 30 oxidation cycles. Although further investigation would be required to understand the oxidation kinetics, it is speculated that the Ir-Ta-Al enriched oxide layer just beneath the surface, as shown in Fig.4(b), may hinder the outward diffusion of $\mathrm{Ni}$, thus retarding the formation of $\mathrm{NiAl}_{2} \mathrm{O}_{4}$ and $\mathrm{NiO}$.

\section{Corrosion resistance}

Having good hot corrosion resistance is another important requirement for coatings of high temperature structural materials. Comparisons of hot corrosion properties have been carried out in this section.

Figure 6 shows the sample weight change as a function of hot corrosion cycles. Similar to the cyclic oxidation tests, the sample weight gain is mainly attributed to the formation of brittle and corrosive products such as sulfides or oxides while weight loss is mainly attributed to the evaporation of volatile oxides or spallation of such brittle and corrosive products as mentioned previously. Therefore, the significant variation in sample weight of the specimens except for ( $\mathrm{Ir}, \mathrm{Ta}$ )-Al-coated and simply aluminized TMS-75 indicates the repeated formation and

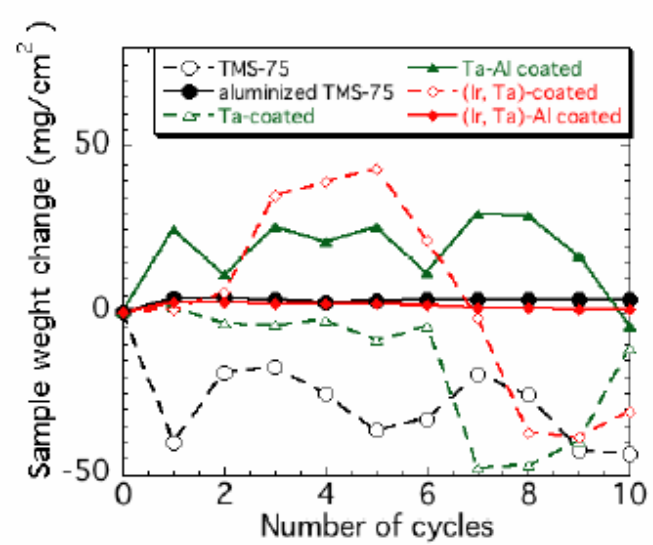

Figure 6: Kinetic corrosion curves of specimens as a function of heating cycle. Specimens were kept at $1173 \mathrm{~K}$ for 20 hours and aircooled for each cycle. 
(a)

(b)
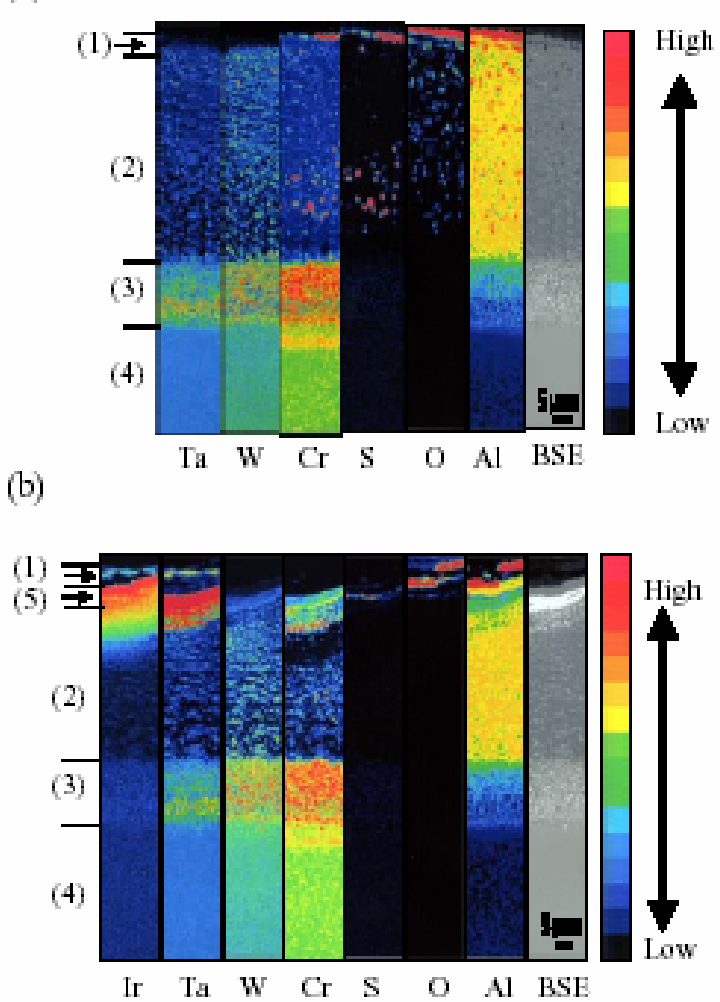

Figure 7: The concentration map of (a) simply aluminized and (b) (Ir, Ta)-Al-coated TMS-75 after hot-corrosion tests; (1) oxide layer, (2) Ni-Al based layer, (3) inner Al-diffusion layer, (4) substrate, (5) Ir-Ta-Al enriched layer.
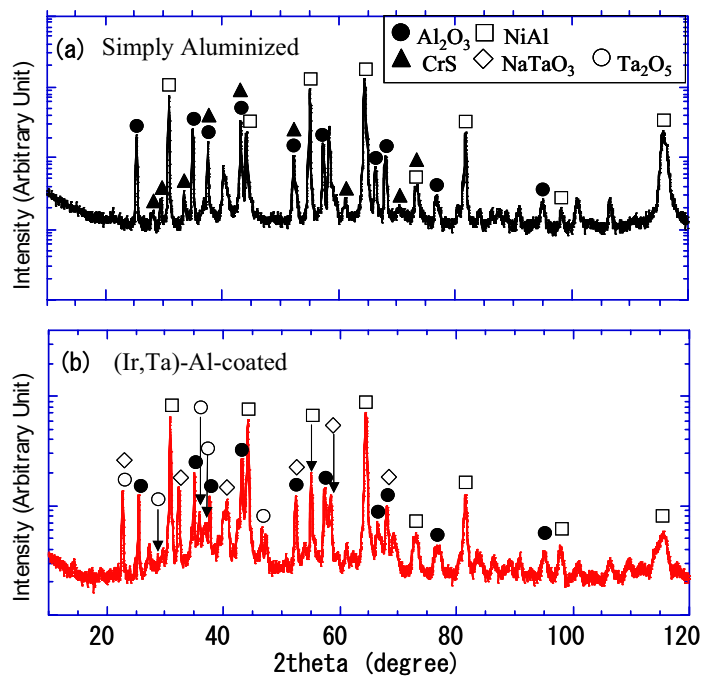

Figure 8: X-ray diffraction profiles of (a) simply aluminized TMS-75 and (b) (Ir, Ta)-Al-coated TMS-75 after hot corrosion tests.

spallation of brittle or corrosive products during corrosion tests, implying the poor corrosion resistance. On the other hand, sample weight changes of both (Ir, Ta)-Al-coated and simply aluminized TMS-75 are similar and smallest, suggesting that they have better corrosion resistance than the others. However, microstructural investigations revealed that they have different morphologies. Backscattered electron (BSE) images with concentration maps of these two specimens, derived from EPMA are shown in Figure 7. In simply aluminized TMS-75, three kinds of layers are observed; an outer oxide layer with a thickness of about $5 \mu \mathrm{m}$ (in Fig.7(a)), an intermediate $\mathrm{Ni}$-Al based layer with a thickness of about $60 \mu \mathrm{m}$ ((2) in Fig.7(a)) and an inner Al-diffusion layer with a thickness of about $30 \mu \mathrm{m}((3)$ in Fig.7(a)) from the surface. Note that in the BSE image, there are a number of dark spots corresponding to cracks or voids. The distribution of these dark spots agrees very well with that of oxygen enriched region. In addition, in the Ni-Al based layer, co-segregation of $\mathrm{Cr}$ and $\mathrm{S}$ is observed as red spots, which propagated to approximately $70 \mu \mathrm{m}$ in depth from the surface. These results indicate that internal oxidation and sulfuration occurred in simply aluminized TMS-75. In the case of (Ir, Ta)-Al-coated TMS-75, on the other hand, an Ir-Ta-Al enriched layer lies in between the oxide layer and the $\mathrm{Ni}-\mathrm{Al}$ enriched layer. The number of cracks and vacancies are much smaller than those in simply aluminized TMS-75. Neither the enrichment of $\mathrm{O}$, nor the co-enrichment of $\mathrm{Cr}$ and $\mathrm{S}$ are observed in the (Ir, Ta)-Al-coated TMS-75 specimens.

Phase identification of the surfaces of the (a) simply aluminized TMS-75 and (b) (Ir, Ta)-Al-coated TMS-75, after the hot corrosion tests was conducted by X-ray diffraction analysis as in Figure 8. $\mathrm{Na}_{2} \mathrm{SO}_{4}$, which was used as the molten salt for the corrosion test, was not identified for either specimen, confirming that the molten salt was thoroughly removed from the surface when the samples were cleaned. $\mathrm{NiAl}$ and $\mathrm{Al}_{2} \mathrm{O}_{3}$ phases were identified on both surfaces of the specimens. In addition, the $\mathrm{CrS}$ phase was identified in simply aluminized TMS-75 whilst not sulfides but $\mathrm{Ta}_{2} \mathrm{O}_{5}$ and $\mathrm{NaTaO}_{3}$ were identified in (Ir, Ta)-Alcoated TMS-75. These results are consistent with the EPMA analysis described above.

From these investigations, it is revealed that (Ir, Ta)-Al-coated TMS-75 has higher corrosion resistance than any other specimens at $1173 \mathrm{~K}$. There may be two major roles of the Ir-Ta layer for improving hot corrosion resistance: i) a diffusion barrier of solute elements as described in the previous section and ii) formation of tantalum oxides to protect the corrosive attacks by $\mathrm{S}$.

It is well established that $\mathrm{S}$ and $\mathrm{O}$ in the molten salts diffuse very quickly at intergranular sites [8]. Especially, S diffuses extremely quickly and attacks grain boundaries, which gives rise to the formation of cracks. Also, when small voids are formed in a coating layer, $\mathrm{O}$ and $\mathrm{S}$ segregate at these small voids to form oxides and sulfides, which may become crack propagation sites. In simply aluminized TMS-75 as explained in the previous section, $\mathrm{Ni}, \mathrm{Co}$ and $\mathrm{Cr}$ easily diffuse outwards. The outward diffused $\mathrm{Cr}$ and $\mathrm{S}$ thus formed $\mathrm{CrS}$ as shown in Fig. 7, which may have enhanced the initiation and propagation of cracks. Although further investigation is required to understand the detailed mechanism of $\mathrm{CrS}$ formation and the reason why only $\mathrm{CrS}$ is detected, it is concluded that many cracks and voids generated in simply aluminized TMS-75 are attributed to the formation of $\mathrm{CrS}$ which would degrade the mechanical properties of the coatings. In (Ir, Ta)-Al-coated TMS-75, on the other hand, $\alpha-\mathrm{Al}_{2} \mathrm{O}_{3}, \mathrm{NiAl}$, $\mathrm{Ta}_{2} \mathrm{O}_{5}$ and $\mathrm{NaTaO}_{3}$ peaks were identified from X-ray analysis. Lee et al. [9] reported that $\mathrm{NaTaO}_{3}$ is formed from $\mathrm{Na}_{2} \mathrm{SO}_{4}$ and $\mathrm{Ta}_{2} \mathrm{O}_{5}$ according to the following reactions: 


$$
\begin{gathered}
\mathrm{Na}_{2} \mathrm{SO}_{4}=\mathrm{Na}_{2} \mathrm{O}+\mathrm{SO}_{3} \\
\mathrm{Ta}_{2} \mathrm{O}_{5}+\mathrm{Na}_{2} \mathrm{O}=2 \mathrm{NaTaO}_{3}
\end{gathered}
$$

Since the melting point of $\mathrm{NaTaO}_{3}$ is $2083 \mathrm{~K}, \mathrm{NaTaO}_{3}$ will not be melted during the hot-corrosion tests and thus will not work as the corrosive agents. In addition, $\mathrm{Ta}_{2} \mathrm{O}_{5}$, a melting point of $2163 \mathrm{~K}$, is known as the stable oxide. In 'Ir-Ta+Al', the presence of both $\alpha$ $\mathrm{Al}_{2} \mathrm{O}_{3}$ and $\mathrm{Ta}_{2} \mathrm{O}_{5}$ on the specimen surface may have protected the surface from so-called "sulfur and oxygen attack" and prevented the formation of sulfides such as CrS and voids. It is also suggested that the Ir-Ta-Al enriched layer hinders the outward diffusion of $\mathrm{Cr}$ to the surface, thus avoiding the reaction between $\mathrm{Cr}$ and $\mathrm{S}$. These results can explain the better corrosion resistance of (Ir, Ta)-Al-coated TMS-75.

\subsection{Oxidation properties of (Ir, Pt)-coated TMS-75}

In the previous section, we have proposed the Ir-Ta coatings as a candidate for the next-generation bond-coat materials. However, practical tubine blade industries will seek low-cost coating technologies. While proposing new materials, we are trying to develop new technologies to deposit Ir-Ta coatings with lower cost. On the other hand, addition of Ir to Pt-modified coatings is of interest because Ir-Pt alloys can be deposited using the electroplating process which we have recently developed [10]. Another advantage is the cost of the materials. Since Ir is cheaper than $\mathrm{Pt}$, Ir deposition would reduce the cost of airfoils, compared to Pt-modified aluminide coatings [11].

Microstructure of as-aluminized specimens

Ir-Pt alloys with various compositions were deposited on TMS-75 followed by the al-pack cementation at $1273 \mathrm{~K}$ for $5 \mathrm{~h}$, Figures 9 and 10 show the cross-sectional microstructure and the concentration distribution of the elements for the $\mathrm{Pt}-\mathrm{Al}$ coated

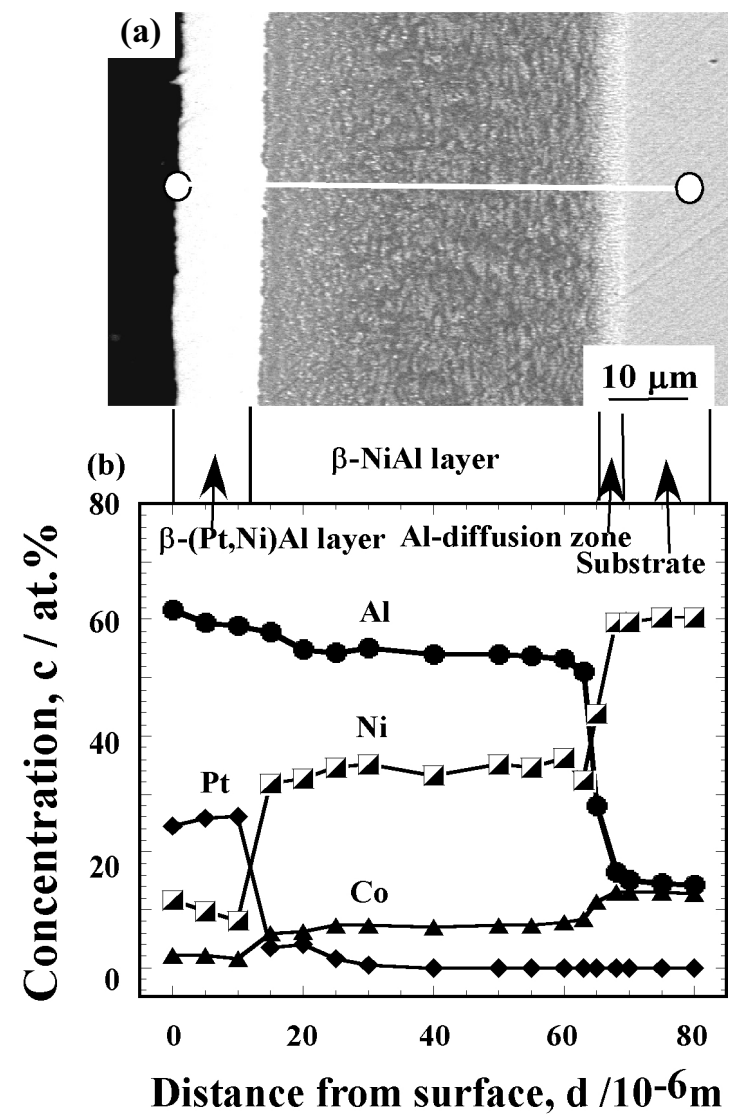

Figure 9: (a)Cross-sectional microstructure and (b) concentration profile of Pt-Al coated TMS-75.
TMS-75 (Fig. 9), Ir-Al coated (Fig. 10) and simply aluminized TMS-75 (Fig. 3), respectively. It can clearly be seen from Fig. 9a and Fig. 10a that the Pt-Al coated and Ir-Al coated TMS-75 have triplex layer structure. XRD and EDS analyses revealed that both the coatings have B2 ordered structure, consisting of three continuous layers: a dense and uniform outer of $\beta$-(Pt,Ni)Al- or $\beta$ (Ir,Ni)Al-based layer $\sim 14 \mu \mathrm{m}$ thick, an intermediate $\beta$-NiAl-based layer $\sim 50 \mu \mathrm{m}$ thick, and an inner Al-diffusion zone $\sim 5 \mu \mathrm{m}$ thick. It should be noted that (Ir, Pt)-Al coated specimens also have a similar structure to that of Pt-Al-coated and Ir-Al coated TMS-75. On the other hand, simply aluminized TMS-75 at $1273 \mathrm{~K}$ showed a very similar structure to that aluminized at $1373 \mathrm{~K}$, except for the thickness of $\beta$-NiAl-based layer $(\sim 60 \mu \mathrm{m}$ at $1273 \mathrm{~K}$ while $\sim 135 \mu \mathrm{m}$ at $1373 \mathrm{~K}$.)

Figures $9 \mathrm{~b}$ and $10 \mathrm{~b}$ illustrate the concentration distribution of the elements measured along the entire cross-section of the sample shown in Fig. 9a and 10a, respectively. For the $\mathrm{Ir}-\mathrm{Al}$ coated TMS-75 (Fig. 10b), the outer $\beta$-(Ir,Ni)Al-based layer contains approximately 56 at.\% of Al, 32 at.\% of Ir together with a small amount of $\mathrm{Ni}(\sim 10$ at.\%) and Co (1 at.\%) which may be attributed to the outward-diffusion from the substrate. The intermediate layer is mainly composed of $\beta$-NiAl with a small amount of $\mathrm{Co}$, Ta and $\mathrm{Cr}$. Some Ir may diffuse inwardly from the coating during the pack-cementation aluminizing process. The inner layer below the $\beta$-NiAl layer is enriched with $\mathrm{Ta}$, and $\mathrm{Cr}$, forming an Al-diffusion zone accompanied by a coarsened $\gamma^{\prime}$ structure. Although having slightly higher Al concentration and lower $\mathrm{Ni}$ concentration in the $\beta$-(Pt,Ni)Al layer, the Pt-Al coated TMS-75 (Fig.10a) demonstrates a similar concentration profile to that of the Ir-Al coated TMS-75. The simply aluminized TMS-75

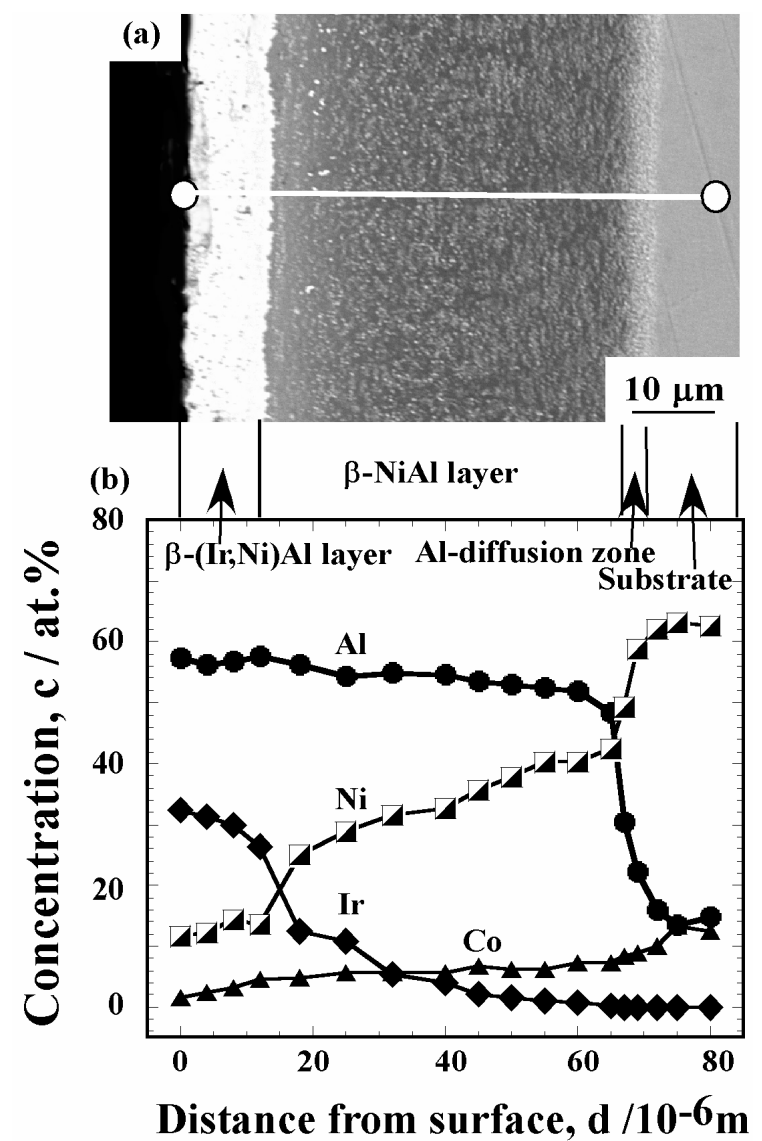

Figure 10: (a)Cross-sectional microstructure and (b) concentration 594profile of Ir-Al coated TMS-75. 
also demonstrates a similar behavior, except for the presence of $\mathrm{Ir}-\mathrm{Al}$ or Pt-Al enriched layers in the former specimens.

\section{Oxidation behavior}

In order to evaluate the stability of oxides formed on the coated specimens under cyclic thermal stresses, a cyclic oxidation test was performed in exactly the same manner as described in the previous section. Specific mass gain as a function of the number of cycles for Pt-Al coated, (36at\%Ir, Pt)-Al-coated, Ir-Al coated and simply aluminized TMS-75 are given in Figure 11. The mass gains of the Pt-Al coated, (36at\% Ir, Pt)-Al coated and $\mathrm{Ir}-\mathrm{Al}$ coated TMS-75 increase monotonically with the increase of oxidation cycles. This indicates that the oxide scales formed on the modified TMS-75 are dense and have good adherence to the coating. On the other hand, in the case of simply aluminized TMS-75, the mass gain increases up to 7 oxidation cycles and then slightly decreases. This indicates that the spallation of the oxide scale from the surface has started after 7 oxidation cycles. In addition, it was found that for each oxidation cycle, the simply aluminized TMS-75 shows larger mass gain than the other specimens, confirming that Ir-Pt alloy deposition retards the growth rate of thermally grown oxides (TGO). Among the coated specimens, the Ir-Al coated one exhibits a slightly higher weight gain rate than $\mathrm{Pt}-\mathrm{Al}$ coated or (36at\% Ir, Pt)-Al coated specimens, yet the maximum mass gain of the $\mathrm{Ir}-\mathrm{Al}$ coated TMS-75 is about half as large as that of the simply aluminized TMS-75. Note that Pt-Al and (36at\%Ir, Pt)-Al showed almost identical oxidation kinetics, suggesting that the growth rate of TGO in $\mathrm{Ir}-\mathrm{Al}$ coated TMS-75 is lower than that in the simply aluminized TMS-75.

Figure 12 shows SEM images of the surface morphologies and cross-sectional microstructures of the specimens after ten oxidation cycles. It can be seen that the surface of simply aluminized TMS-75 is rougher (Fig. $12 \mathrm{~g}$ ) and the oxide scale formed on the surface is thicker $(\sim 10 \mu \mathrm{m})$ and more porous (Fig. 12h) than the others, the oxide scale of which are typically $\sim 3 \mu \mathrm{m}$ thick. In addition, the amount of $\gamma$ '-phase formed under the oxide scale in the simply aluminized TMS-75 is much larger than the other aluminized TMS-75, suggesting that the transformation

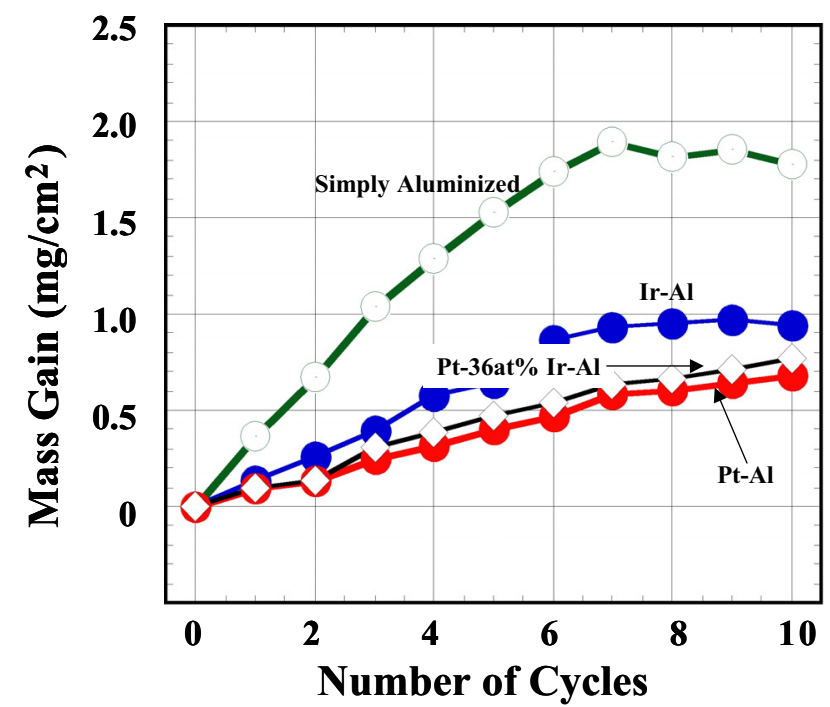

Figure 11: Kinetic corrosion curves of specimens as a function of heating cycle. Specimens were kept at $1373 \mathrm{~K}$ for 20 hours and air-cooled for each cycle.
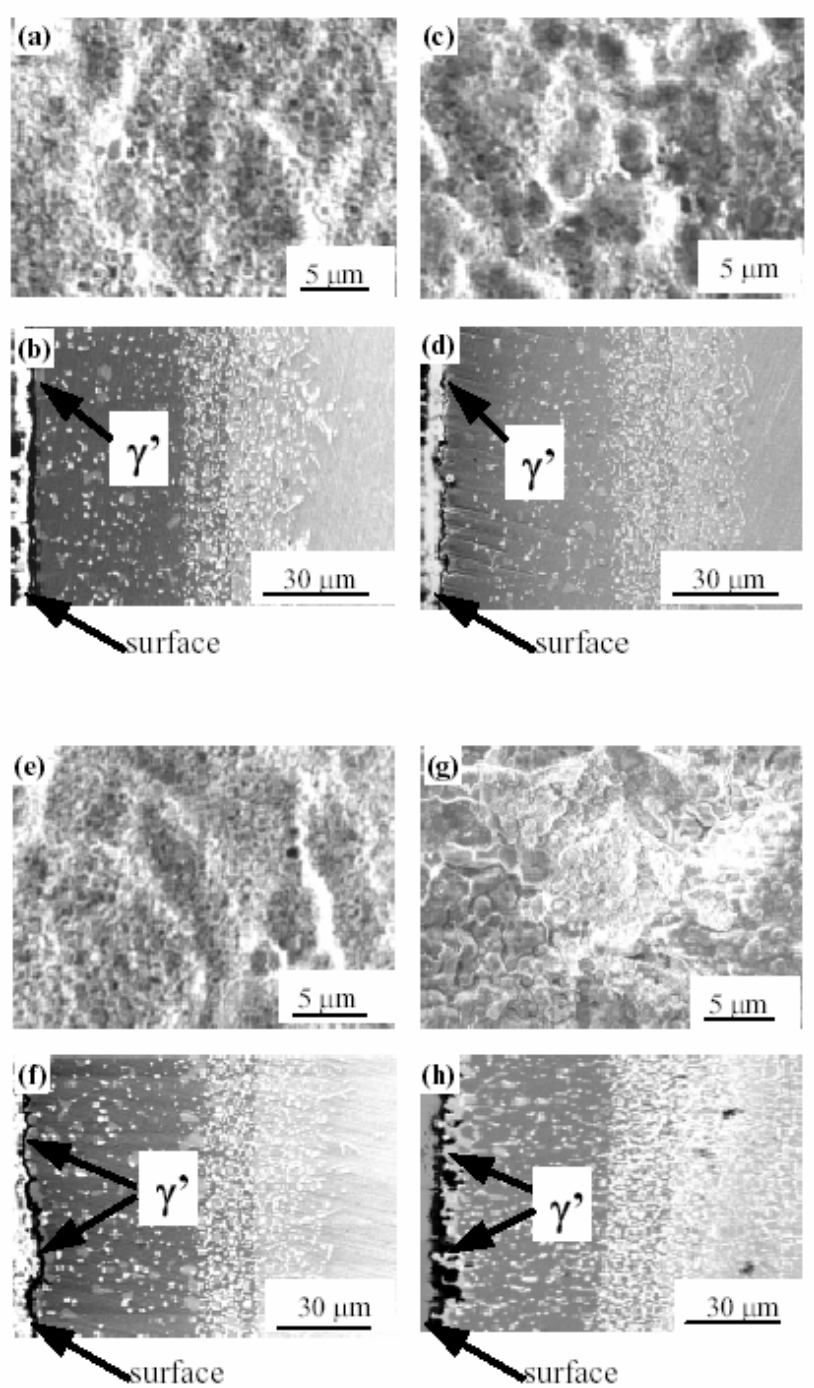

Figure 12 Surface morphologies and Cross-sectional microstructure of (a)(b)Pt-Al coated, (c)(d)(36at\%Ir, Pt)-Alcoated, (e)(f)Ir-Al coated and (g)(h) simply aluminized TMS-

from the $\beta$-NiAl phase to the $\gamma^{\prime}$-phase was decelerated due to the presence of (Pt. Ir, Ni)Al enriched layer. The deceleration of the $\gamma$ '-phase formation is beneficial in improving oxidation resistance of coated specimens, because the $\gamma^{\prime}$-phase does not have good oxidation resistance. When comparing the Pt-Al coated (Fig. $12 \mathrm{a} \& \mathrm{~b}$ ), and Ir-Al coated (Fig. 12e\&f) TMS-75, Pt-Al coated TMS-75 seems to show a smoother surface and smaller amounts of $\gamma$ '-phase precipitates just beneath the oxide scale, indicating that Pt-Al coated TMS-75 has slightly better oxidation resistance. However, it is noteworthy that surface roughness and $\gamma^{\prime}$-phase precipitates are almost identical between, Pt-Al coated and (36at\% Ir, Pt)-Al coated specimens, suggesting that appropriate substitution of Ir for Pt may not affect the oxidation properties of coated materials.

Improved oxidation resistance at high temperature is essential for the next-generation high temperature structural materials and their coatings. They must protect the substrates by forming a dense and adherent oxide scale. The lower mass gain for the Pt-Al-coated, 
(36at\%Ir, Pt)-Al-coated and Ir-Al-coated TMS-75 observed in the kinetic curves of the cyclic oxidation tests suggests the formation of a more dense and adherent oxide scale than that in the simply aluminized TMS-75, which retards the degradation of microstructure. Protective oxide scales kept for longer periods on the Pt-Al-coated, (36at\%Ir, Pt)-Al-coated and Ir-Al-coated TMS75 compared to the simply aluminized TMS-75 lead to higher oxidation resistance.

Although this study revealed that oxidation resistance of an Ir-Al coated TMS-75 is not as good as that of Pt-Al coated TMS-75, Irmodified aluminide coating can be regarded as a promising material for the next-generation turbines because i) addition of $\mathrm{Pt}$ to $\mathrm{Ir}$ in the aluminized coating may act as a solid solution strengthener of the coatings, ii) up to $36 \mathrm{at} \%$ of Ir addition may not deteriorate the oxidation resistance of the coated materials and iii) Ir is known to increase the melting point of substrate Ni-base superalloys [1], thus an Ir coating may not drastically affect the creep properties of substrates, as has been reported in Pt-modified aluminized coatings.

\section{3 Summary}

Through this study, use of Ir for the novel bond-coat material has been proposed, and found that i) Ir-Ta coatings deposited using EB-PVD, followed by aluminization showed better oxidation and hot corrosion resistance than simply aluminized coatings, ii) electrodeposited Ir behaves similarly to $\mathrm{Pt}$, and up to $36 \mathrm{at} \%$ of Ir addition to Pt may not deteriorate the oxidation resistance of the coated materials. In addition, Ir-based alloy coatings in general seem to retard the interdiffusion of solute elements between substrates and coatings. These results confirmed that Ir-based alloys are promising for use as next-generation bond-coat materials. Ir-Ta coatings may be used under high temperature and corrosive atmosphere, and Ir-Pt modified aluminized coatings can straightforwardly replace current Pt-modified aluminide coatings. In order to realize practical usage for these coatings, further investigation would be required. Optimization of the coating parameters and characteristics, such as, composition of Ir-Ta and / or Ir-Pt, and the optimization of aluminizing parameters, in accordance with the characteristics of Ir-based coatings and substrate superalloys, would be utmost importance. Detailed investigations on the distribution of Ir, Ta and Pt presented in the coated materials after cyclic oxidation tests, the diffusion kinetics of solute elements such as $\mathrm{Ir}, \mathrm{Pt}, \mathrm{Ta}, \mathrm{Ni}$, and $\mathrm{Al}$, and the mechanical properties such as creep and fatigue properties of the coatings, should be carried out in the future.

\section{Conclusions}

The results and the subsequent discussions described above support the following conclusions.

1. The Ir-Ta coated TMS-75 with Al-pack cementation showed better oxidation resistance than simply aluminized TMS-75. Moreover, the precipitation of the third phase was suppressed.

2. The hot corrosion tests and the following investigations revealed that in the Ir-Ta coated TMS-75 with Al-pack cementation, an Ir-Ta-Ni-Al enriched layer prevented the infiltration of oxygen and sulfur, and retarded the formation of voids and cracks in the inner layer, confirming that the Ir-Ta coated superalloys with Al-pack cementation also has better corrosion resistance.

3. Cyclic oxidation tests revealed that coated materials having better thermal cyclic oxidation resistance can be arranged in the following order: $\mathrm{Pt}-\mathrm{Al}=(36 \mathrm{at} \% \mathrm{Ir}, \mathrm{Pt}) \mathrm{Al}>\mathrm{Ir}-\mathrm{Al}$
>> simply aluminized. This can be attributed to the presense of $\mathrm{Pt}$ and/or Ir which not only improved the adherence of oxide scale but also retarded the transformation of the $\beta$-(Ir,Ni)Al phase to the $\gamma$ ' phase during oxidation.

4. (Pt, Ir)-Al coatings are promising for replacing conventional Pt-Al ones because Ir may play a role as solid solution strengthener and will not deteriorate the creep properties of substrates, although oxidation resistance of Ir-Al is not as good as that of Pt-Al.Thermal cyclic oxidation resistance of the $\mathrm{Ir}-\mathrm{Al}$ coated TMS-75 is higher than that of simply aluminized TMS-75. This can be attributed to the presense of Ir, which not only improved the adherence of oxide scale but also retarded the transformation of the $\beta$-(Ir,Ni)Al phase to the $\gamma$ ' phase during oxidation.

\section{Acknowledgements}

A part of this work was carried out under the auspices of International Research Grant Program, JAPAN New Energy and Industrial Technology Development Organization (NEDO). The authors wish to thank Toshiba Co. Ltd for assisting Al pack cementation, Mr. K. Nishida for the EPMA analysis. The authors are also grateful to, Mr. T. Yokokawa, Y. Koizumi, T. Kobayashi and M. Sato for their assistance and helpful discussions for conducting this study.

\section{References}

1. H. Murakami et al., "Distribution of Platinum Group Metals in Ni-base Single-Crystal Superalloys", Superalloys, 2000, 747-756

2. Y Koizumi et al., "Third Generation Single Crystal Superalloys with Excellent Processability and Phase Stability", Materials for Advanced Power Engineering proceedings, 1998, 1089-1098.

3. Y. Yamabe et al., "Development of Ir-base refractory superalloys", Scripta Materialia, 35, 1996, 211-215.

4. D. H. Boone et al., "Physical Vapor-Deposition Processes", Mater. Sci. Technol., 2, 1986, 220-224

5. A. Suzuki et al., "Characterization of the Bond-coat Materials for the Super High Efficiency Gas Turbines", Materials for Advanced Power Engineering proceedings, 2002, 535-542.

6. M. J. Stinger et al., "Thermal Barrier Coatings for the $21^{\text {st }}$ century", Z. Metalkd, 90 (1999) 12, 1069-1078.

7. F Wu, A. Suzuki and H. Murakami, "Development of an iridium -tantalum modified aluminide coating as a diffusion barrier on nickel-base single crystal superalloy TMS-75", Surface \& Coatings Technology, 168, 2003, 62-69

8. M. Yoshiba et al., "Effect of Environmental-Factors on the Creep-Rupture Properties of a Nickel-base Superalloy Subjected to Hot Corrosion", Transaction of the Japan Institute of Metals, Vol.29, No.1, 1988, 26-41.

9. Woo Y. Lee et al., "NA2SO4-Induced Corrosion of SI3N4 Coated with Chemically Vapor-Deposited TA2O5", Journal of Am Ceram. Soc., 78, 1995, 7, 1927-1930.

10. Feng $\mathrm{Wu}$ et al., "Electrodeposition of Pt-Ir alloys on Nickel-base Single Crystal Superalloy TMS-75", Surf. and Coat. Tech. in press (2004).

11. G. Fisher et al., "An assessment of the oxidation resistance of an iridium and an iridium/platinum low-activity aluminide/MarM002 system at $1100^{\circ} \mathrm{C}$ " Surf Coat Tech., 113, 1999, 259-267. 